\title{
ÉTICA DA RESPONSABILIDADE E ÉTICA DO DISCURSO: AS PROPOSTAS DE HANS JONAS E KARL-OTTO APEL
}

\author{
Robinson dos Santos \\ Universidade Federal de Pelotas
}

Resumo: Este trabalho pretende apresentar de modo resumido a defesa de uma ética da responsabilidade nas abordagens de Hans Jonas e Karl-Otto Apel. Apesar de concordarem quanto aos problemas emergentes em nossa época e a urgente necessidade de uma ética universal e voltada para o futuro da humanidade, os autores seguem caminhos divergentes em suas respectivas formulações. É necessário situar a perspectiva em que cada um deles se coloca para dar conta do problema. Enquanto para Jonas a preocupação é oferecer uma resposta mais concreta ou prática, Apel trata de resolver o problema primeiramente no plano teórico. Mesmo seguindo caminhos diferentes, são duas perspectivas contemporâneas que se propõem a oferecer uma resposta para os problemas de nossa época. É preciso elucidar se são propostas incompatíveis ou apresentam traços de complementariedade.

Palavras-chave: Ética da responsabilidade, ética do discurso, fundamentação, Jonas, Apel

Abstract: This work intends to present in summarized order the defense of an ethic of responsibility in the approaches of Hans Jonas and Karl-Otto Apel. Despite agreeing on the problems emerging in our time and the urgent need for a universal ethic and looking to the future of humanity, the authors follow divergent paths in their formulations. It is necessary to put the perspective in which each arises in dealing with the problem. As for Jonah's concern is to offer a more concrete answer or practice, Apel tries to resolve the problem first at the theoretical level. Even following different paths, are two contemporary perspectives that purport to offer an answer to the problems of our time. We need to clarify whether proposals are incompatible or have traces of complementarity.

Keywords: Ethic of responsibility, ethic of discussion, reasoning, Jonas, Apel 


\section{Considerações iniciais}

No âmbito da ética, seja ela antiga, moderna ou contemporânea, uma das questões centrais é aquela que trata da fundamentação ou justificação de princípios ou normas morais. Para que se responda de modo seguro e sistemático e, portanto, não fragmentário e precário à pergunta "o que devo fazer?”, que no entender de Kant é aquela que resume todos os esforços no campo da moral, mais do que uma indicação, é necessário oferecer razões.

Com efeito e, até mesmo, para além do campo de investigação filosófica, os seres humanos não se contentam simplesmente em obedecer cegamente e o tempo todo uma regra, autoridade ou instituição, sem que se interpelem a respeito da validade ou legitimidade da mesma. Cortina (2003, p. 79) acertadamente observa que: "Diante da imposição ou da proposição de normas, ante o convite para se seguir determinados ideais de conduta, os homens perguntam - com tanto mais frequência, quanto mais críticos 'porquê?"'.

Deste modo, ao filósofo da moral cabe a tarefa de se posicionar de maneira definida com relação à exigência de apresentar as razões para que determinados princípios ou formas de conduta possam ser aceitos e seguidos por todos os seres racionais.

No cenário filosófico contemporâneo as múltiplas perspectivas ou tentativas de resposta ao problema de se conceber e justificar um princípio para a moralidade sugerem de modo indireto que isso é quase impossível ou que, no melhor dos casos, teremos apenas tentativas menos problemáticas que outras ou, como afirma Tugendhat em suas Vorlesungen über Ethik, respostas mais plausíveis ou menos plausíveis (1993, p. 30) ${ }^{1}$. De um lado este incessante recomeçar ou reelaborar no plano de fundamentação da moral fortalece o caráter eminentemente crítico da filosofia da moral e propicia um aprimoramento dos argumentos, o que resulta num permanente desenvolvimento da própria ética. Por outro lado, a pluralidade de perspectivas sinaliza indiretamente uma crise de orientação que, pode até mesmo reforçar a justificação de uma postura de ceticismo ou relativismo ético ${ }^{2}$.

\footnotetext{
1 Esta obra de Tugendhat está traduzida para o idioma português como Lições sobre Ética.

2 Neste sentido o próprio Tugendhat resume o problema das polarizações: de um lado alguns (ele cita em especial, neste caso, os alemães) continuam acreditando numa forma simples de fundamentação do
} 
As propostas de Hans Jonas, que defende uma ética da responsabilidade, e de Karl-Otto Apel, que procura defender igualmente uma idéia de responsabilidade a partir de sua ética do discurso, apresentam-se, neste debate, como possibilidades para um posicionamento ante à pergunta “o que eu devo fazer?”. Ambos situam-se diante do problema da civilização contemporânea, marcada desde o início do século passado por guerras e pela escalada nuclear, pela crescente crise ecológica, como preço da civilização industrial, enfim pelo predomínio de uma racionalidade cientificista que, de certa forma, procura reduzir problemas morais à questões relacionadas à subjetividade, ou a questões de preferências pessoais ou emocionais e, portanto, irracionais.

Enquanto Jonas oferece um tratamento para a questão que parte do descompasso entre as éticas da tradição e os desafios totalmente novos de nossa época, apresentando a responsabilidade como dever fundamental do ser humano, sobretudo para com as gerações futuras, Apel privilegia o enfrentamento do problema de uma fundamentação última de princípios e normas morais. Segundo Apel o conflito fundamental de nossa época é que ela está marcada simultaneamente pela necessidade de uma ética universal e a aparente impossibilidade de se estabelecê-la. Partindo desta consideração ele reflete sobre a ética do discurso como possibilidade de saída para tal impasse. De modo sucinto: ambos partem de uma preocupação comum e pretendem oferecer um princípio, porém com uma substancial diferença no que se refere à justificação de suas propostas.

Neste trabalho o objetivo é oferecer uma breve caracterização de tais propostas, sem adentrar no vasto e complexo âmbito global de suas respectivas obras. Visa-se primeiramente a identificação do que ou do quanto há em comum no ponto de partida de suas respectivas argumentações, para em seguida demarcar em que plano se situam suas divergências. A partir disso teremos alguns subsídios para avaliar sua possível incompatibilidade ou seu possível caráter complementar.

juízo moral, nos moldes aproximados da moral fundamentada na religião, onde o princípio permanece indiscutível e exige um ato de fé. Estes, observa ele, desfrutam de uma grande popularidade. Por outro lado, boa parte dos filósofos da moral (aqui a referência é aos anglo-saxões em especial) entendem que a pergunta pelo princípio da moral ou por sua fundamentação não tem qualquer sentido.(Op. cit., p. 25) 


\section{Hans Jonas e a ética da responsabilidade}

a) Diagnóstico de nossa época

Hans Jonas procurou estabelecer em Das Prinzip Verantwortung Versuch einer Ethik für die technologische Zivilisation ${ }^{3}$ (1979) um novo imperativo para ética ou, como ele mesmo caracateriza, uma ética para a civilização tecnológica ${ }^{4}$. Partindo da idéia de que, por meio da técnica, a condição humana se modificou drasticamente, Jonas entende que as éticas da tradição não são suficientes hoje - o que não significa inválidas - para enfrentarmos os problemas novos que se originam do agir humano, cuja natureza foi modificada. Com efeito no prefácio de PV ele assim se pronuncia:

A tese de partida deste livro é que a promessa da tecnologia moderna se converteu em ameaça, ou esta se associou àquela de forma indissolúvel. [...] Nenhuma ética tradicional nos instrui, portanto, sobre as normas do 'bem' e do 'mal' às quais se devem submeter as modalidades inteiramente novas do poder $\mathrm{e}$ de suas criações possíveis. O novo continente da práxis coletiva que adentramos com a alta tecnologia ainda constitui, para a teoria ética, uma terra de ninguém. (PV, p. 21)

O descompasso entre o crescimento quantitativo da humanidade com seu crescimento qualitativo, isto é, seu desenvolvimento espiritual, parece ser o ponto crítico para o qual Jonas volta seu olhar ao elaborar este diagnóstico. Para ele decididamente a capacidade do homem fazer se sobrepôs à capacidade de conhecer e saber, bem como de atribuir valor. Ele defende a superação do homo sapiens pelo homo faber. E, por isso, em defesa desta visão, ele argumenta que:

Quando mais necessitamos de sabedoria é quando menos acreditamos nela. Quando, pois, a natureza nova do nosso agir exige uma nova ética de responsabilidade de longo

\footnotetext{
${ }^{3}$ Este texto de Jonas será doravante citado de modo abreviado com a sigla PV, que indica o nome principal da obra, isto é, Prinzip Verantwortung (Princípio Responsabilidade).

${ }^{4}$ Para uma leitura complementar a esta, vale conferir SANTOS, 2009, pp. 269-291.
} 
alcance, proporcional à amplitude de nosso poder, ela então também exige, em nome daquela responsabilidade uma nova espécie de humildade - uma humildade não como a do passado, em decorrência da pequenez, mas em decorrência da excessiva grandeza de nosso poder, pois há um excesso do nosso poder de fazer sobre o nosso poder de prever e sobre o nosso poder de conceder valor e julgar. (PV, p. 63)

A subjugação da natureza pelo homem, processo tão antigo quanto o próprio homem, teve um impulso e um acréscimo que não se pode ignorar nos séculos mais recentes mas, com isso, houve também um aumento em tal desproporção do nosso poder que, segundo o autor, não conseguimos mais dimensionar. Além do mais, é de agora em diante que começamos a identificar de forma mais nítida os danos e efeitos colaterais do modelo de desenvolvimento estabelecido e seguido por nossas sociedades, especialmente as ocidentais. Em outras palavras, a vulnerabilidade da natureza começa a ser aceita como a nossa vulnerabilidade. É a partir deste problema, que aqui é posto de modo bem resumido que ele vai desenvolver sua proposta de um novo princípio moral.

\section{b)Fundamentação da ética}

Segundo Jonas as éticas da tradição devem ser corrigidas, pois todas centraram-se numa perspectiva antropocêntrica e voltadas para o presente. Esse enfoque na relação do ser humano apenas com sua espécie (consigo mesmo), deixando de fora das preocupações a consideração, por exemplo, da natureza e de tudo o que compõe o entorno do mundo humano, é uma limitação inaceitável para o autor. É necessário estender ou ampliar o alcance das preocupações e, portanto, tornar objeto da ética também a relação do homem com a natureza, com todo o mundo extra-humano, pois ali também é necessário uma orientação não apenas técnica ou estratégica mas, cada vez mais, nitidamente de caráter moral. "A natureza como uma responsabilidade humana é seguramente um novum sobre o qual uma nova teoria ética deve ser pensada"(PV, p. 39)

Além disso, o autor observa que é implicitamente aceito pela tradição o postulado uma essência humana imutável, isto é, a imagem de que o homem é fundamentalmente o mesmo em todas as épocas e lugares. Por não incluírem o futuro distante e desconhecido como tema de suas preocupações 
as éticas tradicionais são caracterizadas como éticas da proximidade ou simultaneidade, isto é, nas quais são objeto de preocupação os efeitos previsíveis num curto espaço de tempo e relativamente próximo dos sujeitos agentes, especialmente enquanto indivíduos agentes e não como coletivo. Em outras palavras, a noção de responsabilidade moral na tradição recairia mais sobre o indivíduo e menos sobre o coletivo. Neste sentido é que Jonas advoga uma despedida do ideal moderno de uma civilização do progresso, o que o faz rejeitar até mesmo a idéia kantiana de uma razão imanente na história humana ${ }^{5}$. A estas características soma-se a crítica de Jonas ao pensamento utópico do marxismo, em especial ao Princípio Esperança de Ernst Bloch, pelo fato deste ancorar no progresso técnico a emancipação humana e a consequente realização de uma sociedade livre (lazer), na qual os indivíduos, então libertos do fardo do trabalho compulsório, poderiam desenvolver suas verdadeiras vocações.

Jonas não desconsidera que existe um conceito de responsabilidade moral que implica na imputabilidade das ações, isto é, a responsabilidade sobre o ações que foram realizadas e pelas quais os agentes devem responder. Esta é a assim chamada responsabilidade ex post facto (PV, p. 167). Mas aquela a qual o autor se refere diz respeito ao que se deve fazer, não por conta das consequências que dela decorrerão, mas em função "do objeto que reinvindica meu agir”.

O poder se torna, assim, objetivamente responsável por aquele que lhe foi confiado e afetivamente engajado graças ao sentimento de responsabilidade: no sentimento, aquele que obriga encontra seu nexo com a vontade subjetiva. Mas a tomada de partido sentimental tem sua primeira origem não na idéia de responsabilidade em geral, mas no reconhecimento do bem intrínseco do objeto, tal como ele influencia a sensibilidade e envergonha o egoísmo cru do poder. Em primeiro lugar está o dever ser do objeto; em segundo, o dever agri do sujeito chamado a cuidar do objeto. A reinvindicação do objeto, de um lado, na insegurança de sua existência, e a consciência do poder, de outro, culpada da sua causalidade, unem-se no sentimento de responsabilidade

\footnotetext{
5 Ver sobre isso o texto de APEL, 2007, p. 134.
} 
afirmativa do eu ativo, que se encontra sempre intervindo no Ser das coisas. (PV, p. 167).

Jonas entende que o compromisso moral do homem consigo e com a natureza é com a realização de suas respectivas finalidades imanentes (pensamento teleológico). É sobre uma visão ontológico-teleológica que ele procura sustentar sua proposta. Neste sentido, na contracorrente da ética kantiana ele tenta defender um dever constituído a partir do ser, algo que é denominado como a falácia naturalista na ética contemporânea. Este é um dos pontos mais discutíveis da ética jonasiana pois, na contramão de um procedimento que foi justamente banido do campo de justificação da moral, ao menos desde Kant, ele opera numa mescla entre os planos do ser e do dever-ser.

A natureza, segundo ele, persegue finalidades em tudo o que faz e isso confere a ela uma capacidade própria ou uma dinâmica própria que o homem deve respeitar, pois esta capacidade para finalidades seria exatamente aquilo que confere à natureza uma dinâmica própria ou imanente (no entender de Jonas uma subjetividade da natureza p. 136-138) e, sendo assim, a natureza teria, por meio dela, um valor intrínseco. Jonas agumenta no terceiro capítulo de PV que "há, pois, um 'agir' na natureza" (PV, p. 128). Na sua compreensão a eficiência dos fins não deve ser vista apenas como algo vinculado a racionalidade, reflexão e livre escolha, ou seja, não poderia ser restrita ao homem. Em seguida cito três passagens onde o autor apresenta suas ponderações: "Queremos - em última análise, em função da ética ampliar o lugar ontológico da finalidade como um todo, partindo daquilo que se revela na manifestação mais aguçada do sujeito até chegar àquilo que se encontra oculto na espessura do Ser [...]"(PV, p. 136). A partir disso, devese compreender que a subjetividade não seria apenas uma peculiaridade de seres racionais, mas ela é uma dimensão constitutiva da própria natureza em geral, na medida em que esta disposição para realizar finalidades atua "desde dentro" objetivando-se no mundo natural.

Assim como a subjetividade é, em certo sentido, uma manifestação superficial da natureza - a ponta visível de um iceberg muito maior -, ela fala também em nome do seu interior mudo. Ou: o fruto revela algo da raiz e do caule dos 
quais ele proveio. Visto que a subjetividade demonstra um fim eficiente, do qual ela vive inteiramente, precisamos reconhecer que esse interior mudo que só por meio dela ganha fala - ou seja, a matéria - já tem de conter em si um fim, ou algo análogo, sob forma não subjetiva.(PV, p. 136)

E mais adiante ele corrobora esta idéia afirmando que:

[...] da mesma forma como a subejtividade manifesta (que também é sempre particular) é algo assim como um fenômeno que emerge na superfície da natureza, ela se encontra enraizada nessa natureza e em continuidade essencial com ela, de modo que ambas participam do 'fim'(PV, p. 139).

É preciso chamar a atenção para o fato de que o que move Jonas desde o princípio na sua formulação é sua filosofia da biologia. Por isso, é compreensível que a ênfase seja dada à natureza, o que, por sua vez, confere uma certa novidade neste aspecto de sua ética em relação às éticas tradicionais que, como vimos, foram por ele criticadas como antropocêntricas. A vida é para Jonas o valor fundante de toda a ética. A vida diz sim a ela mesma e através de seu porta-voz privilegiado, o ser humano, isso se torna um compromisso, um dever-ser.

\section{Apel e a defesa da responsabilidade a partir da ética do discurso}

\section{a) Diagnóstico de nossa época}

Em seu trabalho intitulado $O$ apriori da comunidade de comunicação e os fundamentos da ética: sobre o problema de uma fundamentação racional da ética na era da ciência ${ }^{6}$, onde Apel discorre sobre a necessidade e a possibilidade de uma fundamentação última para a ética, ele parte de um diagnóstico em que o problema é colocado primeiramente em perspectiva teórica de modo muito perspicaz. Ele remete para aquela situação que foi mencionada no início deste trabalho, isto é de uma necessidade de orientação

${ }^{6} \mathrm{O}$ texto referido texto de Apel está contido no final do segundo volume da obra Transformação da Filosofia (Transformation der Philosophie) abreviado aqui como "TF". 
segundo princípios e a aparente impossibilidade de se fundamentá-los, o que Apel define como a paradoxalidade de nossa época. Em suas palavras:

[...]de um lado, a carência de uma ética universal, ou seja, de uma ética obrigatória para a sociedade humana como um todo, jamais foi tão urgente quanto em nossa era de uma civilização unificada, planetária e criada pelas consequências da ciência. Por outro lado, a tarefa filosófica de uma fundamentação racional da ética univeral jamais pareceu tão difícil e tão sem perspectiva quanto na era da ciência[...] (TF, p. 407)

O aspecto paradoxal é que esta ética universal vinculante para toda a humanidade é necessária mais do que nunca, porém, parece, ao mesmo tempo, ser impossível. Isto porque na época em que impera o modelo de racionalidade objetivo-cientificista que se pretende isenta de valores, toda proposição que não pode ser comprovada empiricamente ou deduzida lógica e formalmente, assim supõe-se, permanece sem sentido e, portanto, tomada como irracional ${ }^{7}$. Para Apel este é o primeiro e grande problema para se enfrentar quando se quer defender de modo coerente uma proposta de fundamentação da ética. Antes de se defender uma teoria da responsabilidade moral é preciso justificar é possível, acima de tudo, fundamentar a validade de normas morais. Além deste aspecto de fundamentação, isto é, além do problema teórico, somam-se as dificuldades de caráter prático. Apel concebe, semelhante a Jonas, que o alcance das consequências tecnológicas da ciência ampliaram o espectro das ações humanas de tal modo que não é mais possível uma regulação ou orientação da convivência humana por meio de normas morais de pequenos grupos.

Neste sentido, ele também entende e defende a necessidade de uma macroética da humanidade. A pergunta crucial para a qual Apel chama atenção neste contexto prático é se as sociedades industriais poderão sobreviver sem uma auto-limitação ética. O problema que ele detecta e, assim, todo aquele que pensa neste contexto das sociedades industriais, é que não se trata apenas de se chegar a uma solução política para o problema por meio da regulamentação dos conflitos sociais no interior do estado e promovendo

\footnotetext{
7 Uma argumentação detalhada deste aspecto pode ser encontrada, entre outros, nos textos de Apel, da coletânea Estudos de moral moderna, indicados aqui por meio da sigla "EMM".
} 
um entendimento ou acordo de relações baseadas na justiça e no respeito mútuo entre os estados. Há um conflito que, segundo Apel, transcende, de fato, este âmbito: trata-se do conflito "de novo gênero, entre o ser humano e a natureza”(ER, p. 133) ${ }^{8}$. A bomba atômica é apenas um exemplo, entre outros, que permite vislumbrar este novo tipo de conflito. Ou seja, está claro para Apel que o aspecto ético-prático em relevo aqui é a existência humana como um todo que está progressivamente ameaçada (TF, p. 409.).

A civilização tecnocientífica confrontou todos os povos, raças e culturas com uma problemática ética comum sem levar em conta suas tradições morais relativas à cultura e específicas de cada grupo. Pela primeira vez na história do gênero humano, os seres humanos foram postos, na prática, diante da tarefa de assumir a responsabilidade solidária pelos efeitos de suas ações em um parâmetro que envolve todo o planeta. (TF, p. 410)

Não há dúvidas quanto ao aspecto comum do problema aqui colocado por Apel com o diagnóstico elaborado por Jonas, já citado anteriormente. A ciência e a técnica levam a um desenvolvimento em que o que se alcança não é apenas o fim representado ou o objetivo posto inicialmente. Pelo contrário, também aqueles fins que não estavam previstos inicialmente passam a ser desenvolvidos pela consecução dos previstos. Isto é, em certo sentido, o homem não tem o controle dos malefícios que determinados benefícios podem trazer contrabandeados consigo.

\section{b)Ética do discurso como ética da responsabilidade}

A proposta de fundamentação da ética apeliana é esboçada no texto já mencionado ( $O$ apriori da comunidade de comunicação), mas retomada em diversos momentos e textos posteriores. A grosso modo, a proposta de uma fundamentação última calca-se na transformação discursiva da ética de Kant, a qual é levada adiante também por Habermas, outro expoente da ética do discurso, porém com um ponto de chegada algo diferente de Apel. Apel quer demonstrar que a argumentação racional "pressuposta não apenas em cada ciência, mas também em toda a discussão de problemas - pressupõe também

${ }^{8}$ APEL, K.-O. Ética e Responsabilidade. O problema da passagem para a moral pós-convencional, 2007. Daqui para frente abreviado como "ER". 
ela, a validação de normas éticas universais” (TF, p. 449). Reportando-se ao factum da razão kantiano, Apel postula que o apriori da comunicação é intransponível, isto é, não podemos retroceder para um estágio anterior a ele. Neste sentido o factum da ética do discurso seria a própria linguagem e o processo comunicativo (argumentativo) como condição de possibilidade de toda e qualquer proposição de princípios para a moral.

[...] qualquer pessoa que propõe a pergunta (plenamente sensata, a meu ver) acerca da justificação do princípio moral já toma parte na discussão, e diante de uma tal pessoa, é possível [...] 'fazê-la ver' o que ela já vinha aceitando 'desde o início’ como um princípio fundamental; e fazê-la ver também que deve aceitar esse princípio, através de sua resoluta corroboração, como uma condição de possibilidade e de validade da argumentação. Quem não vê tal coisa, ou não a aceita, retira-se da discussão.(TF, p. 476-477).

A fundamentação apeliana da ética culmina na legitimação de um princípio regulador que o autor define como a comunidade ideal de comunicação. Esta serve como referência para a comunidade real de comunicação, na medida em que deve ser progressivamente realizada por ela. Não resta dúvidas de que a comunidade real e sua sobrevivência são condições sine qua non da comunidade ideal de comunicação, mas esta é efetivamente o telos a ser alcançado por aquela.“[...] em primeiro lugar, deve se tratar, em todo agir e deixar de agir, de garantir a sobrevivência da espécie humana, como também da comunidade de comunicação real; e, em segundo lugar, de concretizar, na comunidade real, a comunidade de comunicação ideal' (EMM, p. 157).

É, porém, num texto posterior a $O$ apriori da comunidade de comunicação que Apel vai tecer suas críticas à ética de Hans Jonas. O trabalho, apresentado em um congresso sobre o tema sociedade industrial e ética do futuro, posteriormente incluído na coletânea Diskurs und Verantwortung tem como título: Responsabilidade hoje: somente um princípio da conservação e auto-limitação ou ainda de libertação e realização da humanidade?. Apel afirma que não está convencido sobre a tese de Jonas acerca da extinção da reciprocidade numa ética do futuro. 
Os exemplos-modelos de Jonas, a responsabilidade dos progenitores pelos filhos e a responsabilidade dos homens de Estado pelo bem-estar dos cidadãos e cidadãs que lhe estão confiados não demonstram, em meu entender, que a responsabilidade não seja uma relação de reciprocidade. Mas eles demonstram antes que a responsabilidade de princípio dos seres humanos uns pelos outros é uma relação potencial que só se torna atual em conformidade com um efetivo avanço do poder. É assim que acontece com a responsabilidade que, por exemplo, os montanhistas têm uns pelos outros numa equipe de escalada. (ER, p. 145-6)

A fundamentação do dever a partir do Ser em Jonas é aos olhos de Apel ilegítima e, até mesmo, desnecessária. O que para ele é válido da reinvidicação de Jonas é que de acordo com nosso poder cresce também nossa responsabilidade e, com isso legitima-se o "tu deves, logo tu podes". Mas justamente aqui é que Apel pondera que a aceitação de uma obrigação só pode se dar com base "em discursos reais ou simulados dos atingidos ou de seus representantes sobre as consequências e os efeitos secundários da observação de normas propostas.” (ER, p. 146). E para que isso aconteça, isto é, para que isso seja legítimo e obrigatório, Apel entende que há um princípio mais profundo com o qual todos nós estamos confrontados desde sempre, qual seja, "à participação na organização desta responsabilidade enquanto responsabilidade solidária conforme a um princípio formal de uma reciprocidade universalizada" (ER, p. 146).

Partindo destas considerações, Apel propõe que a fundamentação da ética só pode ser levada adiante de modo sistemático se considerarmos que ao nos pronunciarmos de forma racional e argumentativa "já reconhecemos uma ética do discurso ou da responsabilidade, no sentido da reciprocidade universalizada de uma comunidade de comunicação potencialmente ilimitada”(ER, p. 149)

Para caracterizar de forma sucinta (não posso me deter aqui numa discussão pormenorizada da ética apeliana) a fundamentação da ética de Apel, poderíamos assim resumir:

1.O reconhecimento da linguagem como medium intransponível (transcendental) de todo argumentar, de todo o sentido e validade. Este reconhecimento é necessário e universal, pois mesmo aquele que queira 
refutar este postulado não pode fazê-lo sem o pressupor de antemão (Contradição performativa).

2. As condições transcendentais do discurso são condições de possibilidade do objeto do discurso. Para que a argumentação possa ter sentido e validez intersubjetiva é necessário: a) que se cumpram as regras intersubjetivas do uso linguístico da comunidade em que se está envolvido (ponto de vista sintático); b) que as proposições sejam compreensíveis e, assim, tornem acessível o objeto da argumentação e possibilitem o acordo intersubjetivo (dimensão semântica e pragmática).

3. Deste modo quem argumenta levanta pretensões de validade intersubjetivas: (verdade, correção, veracidade).

A ética do discurso defende o princípio moral da reciprocidade dialógica universal. Conforme Herrero (2000, p. 173) isso significa:

[...]na argumentação surge o dever recíproco de fazer valer exclusivamente argumentos e nenhuma outra instância alheia à argumentação, isto é, nada pode ser reinvindicado como válido a não ser aquilo que possa ser fundamentado discursiva e responsavelmente por argumentos e, portanto, o dever de resolver dialógica e argumentativamente todas as pretensões à validade da vida humana, do qual resulta que todo conteúdo que se apresentar como digno de ser reconhecido como válido terá que ser, em princípio, capaz de consenso.

A ética do discurso é declaradamente herdeira da ética kantiana, mas transforma o que, em sua visão, é problemático em Kant. A transformação é concebida como a passagem de uma filosofia da subjetividade (consciência) para uma filosofia da intersubjetividade, dialógica, calcada na linguagem.

Deste modo, Apel entende, por exemplo, que o problema da humanidade futura não fica excluído na ética do discurso na medida em que, por meio de uma antecipação contrafática de uma comunidade de comunicação ideal ilimitada, podemos reconhecer que as soluções legítimas para os problemas em questão devem ser capazes de consenso. É aqui que a ética do discurso se declara uma ética da responsabilidade solidária pela solução de problemas e defende a igualdade de direitos na solução de problemas, numa comunidade de comunicação real. Por meio da antecipação contrafática, diz Apel, ganha-se mais um postulado eticamente relevante: "que 
na comunidade de comunicação real da humanidade, a comunidade ideal terá que ser sempre - progressivamente - realizada”.(ER, p. 151)

\section{Retrospectiva}

A partir desta caracterização das duas propostas e para finalizar este ensaio, gostaria de apresentar as seguintes observações:

a) O diagnóstico de nossa época, marcada pela racionalidade técnicocientífica e, portanto, pela consequente relativização de questões morais, bem como pela necessidade cada vez mais aguda de uma macro-ética válida para a humanidade e que oriente não apenas as relações entre os seres humanos, mas entre estes e a biosfera e assegure a viabilidade de uma vida boa (digna) para as gerações futuras é o que move inicialmente os dois autores a pensarem numa ética cuja noção de responsabilidade inclua a preocupação com o futuro. Tanto em uma perspectiva quanto em outra há claramente uma pretensão normativa. $\mathrm{Na}$ ética do discurso a atenção é especialmente voltada para o problema da fundamentação, onde é postulado o apriori da comunidade de comunicação como condição de possibilidade da proposição de qualquer princípio ou norma. $\mathrm{Na}$ ética da responsabilidade de Hans Jonas temos o deslocamento do homem como centro das preocupações morais, passando a ser tomada a vida ou o cosmos na sua totalidade como núcleo das preocupações. O imperativo categórico de Kant é reformulado na perspectiva de um dever de que a humanidade continue existindo, pois só esta é capaz de zelar pela continuidade da vida no planeta.

b)A ética da responsabilidade de Jonas visa uma resposta concreta aos problemas práticos (os perigos que ameaçam a humanidade). Não está em questão para Jonas a felicidade ou a perfeição moral do ser humano, ou a justiça. Pode-se, até mesmo, detectar a ausência de uma proposta política mais clara em seu pensamento, assim como a falta de uma elaboração promenorizada dos desdobramentos ou implicações de sua proposta na esfera do direito. É uma ética que poderíamos classificar provisoriamente de negativa, isto é, uma ética que visa antes a preservação ou conservação, o cuidado e a salvação do homem presente e futuro e do planeta inteiro. Ela não dá recomendações diretas do que fazer em cada situação, mas convoca à precaução (heurística do temor). Com isso o objetivo não é promover o bem de forma direta, mas fazê-lo evitando o mal, desviando dos perigos e riscos que podemos vislumbrar. Mas é preciso admitir que isso ainda permanece 
bastante genérico, uma vez que a própria noção de bem ou mal sofre modificações em diferentes momentos históricos e em diferentes espaços. Outro aspecto problemático é que, ao ancorar sua ética em uma ontologia teleológica Jonas parece retornar à metafísica dogmática, recolocando o problema da falácia naturalista, já não mais aceito como programa de fundamentação nos tempos atuais.

c) Um dos questionamentos mais importantes levantados por Apel a Jonas referente a ética da responsabilidade é justamente em torno da conservação ou preservação da dignidade. Nesta perspectiva ele argumenta que:

[...] mesmo quando, juntamente com Jonas, se partilha a opinião de que o importante na situação atual é salvar a existência, portanto a sobrevivência, e a imagem essencial intacta, portanto a dignidade dos perigos que se encontram no mero avanço do progresso, ou seja do processo de industrialização em curso, mesmo quando se é dessa opinião, e para tal eu também me inclino, também se poderá indagar se a existência e a dignidade humanas serão possíveis de salvar por meio da mera conservação das condições atuais. Mais precisamente: não será a natureza do homem e o seu meio ambiente, desde há muito tempo moldado técnica e sócioculturalmente, constituída de tal maneira que ela sem uma idéia reguladora do progresso tecnológico e social não pode ser conservada? A possibilidade de uma conservação ética da dignidade humana nãoe estará a priori associada a condição de que ela também ainda terá de ser primeiramente realizada em particular no sentido de uma produção à escala mundial de relações sociais humanamente dignas? (ER, p. 135).

d) A ética do discurso visa dar conta primeiramente do problema da fundamentação da moral, o que Apel vai definir como a parte $A$ ou abstrata da ética. Embora Apel conceba a ética do discurso igualmente como uma ética da responsabilidade solidária, é importante salientar que o alvo de Apel é fazer frente à argumentação do cético que nega qualquer possibilidade de se fundamentar um princípio moral. É na parte $B$, relacionada ao contexto histórico (Geschichtsbezogen) que serão tratados os aspectos concretos e situacionais. 
e) Ao privilegiar uma relação não-simétrica e não-recíproca podemos afirmar que Jonas efetivamente traz algo novo para o campo da ética. Esta é a posição de Wolfgang Kühlmann, um dos atuais expoentes da ética do discurso situados na perspectiva apeliana. Ao centrar-se diretamente sobre os envolvidos no discurso, fundamentalmente em igualdade de condições e com iguais direitos de se pronunciarem, a ética do discurso se não fecha a esta possibilidade, não impede que se a tome como objeto das discussões, mas também não a tematiza de modo direto. Outro ponto importante trazido à luz por Jonas é a inclusão direta do problema ecológico como problema central para a ética. É claro que isso evidencia, novamente, uma preocupação mais prática e menos teórica ou normativa.

f) Apel argumenta, no entanto, que : "A fundamentação última da ética do discurso contém, portanto (...), também uma fundamentação racional do postulado fundamental de Hans Jonas, que também no futuro deverá haver uma humanidade(...)"(ER, p. 151). Com isso, Apel acredita algo com o que até o momento tendemos a concordar - que seu esforço em oferecer uma resposta ao tema da responsabilidade para com as gerações futuras, é mais consequente e menos problemático (ainda que Habermas levante fortes objeções à sua proposta), tanto do ponto de vista da fundamentação de um princípio, quanto de sua aplicação prática. Isso não invalida nem diminui, todavia o valor provocativo da ética da responsabilidade de Jonas, na medida em que ao se tratar deste tema na atualidade, concordando ou discordando, não pode ignorar os problemas para os quais ele chama atenção. 


\section{Referências}

APEL, K.-O. Diskurs und Verantwortung. Das Problem des Übergangs zur postkonventionellen Moral. Frankfurt am Main: Suhrkamp, 1988.

. Transformation der Philosophie Bd. I/II. Frankfurt am Main: Suhrkamp, 1995; 1999.

. Transformação da Filosofia (2 Volumes). Trad. Paulo Astor Soethe. São Paulo: Loyola, 2000.

. Estudos de moral moderna. Trad. Benno Dischinger. Petrópolis: Vozes, 1994.

Ética e responsabilidade: o problema da passagem para a moral pósconvencional. Trad. Jorge Telles Menezes. Lisboa: Instituto Piaget, 2007.

BECCHI, P.. La ética en la era de la técnica. Elementos para una crítica a Karl-Otto Apel y Hans Jonas. In: Doxa Cuadernos de Filosofía del Derecho. Universidad de Alicante, 1989.

GALIMBERTI, U. Psiche e Techne: o homem na idade da técnica. Trad. José Maria de Almeida. São Paulo: Paulus, 2006.

JONAS, H. Dem bösen Ende näher. Gespräche über das Verhältnis des Menschen zur Natur. Hrsg. von Wolfgang Schneider.Frankfurt am Main: Suhrkamp, 1993.

Das Prinzip Verantwortung :Versuch einer Ethik für die technologische Zivilisation. Frankfurt am Main: Suhrkamp, 1984.

SANTOS, R. "O problema da técnica e a crítica à tradição na ética de Hans Jonas". In: Revista Dissertatio, n. 30, 2009 (p. 269-291).

TUGENDHAT, E. Vorlesungen über Ethik. Frankfurt am Main: Suhrkamp, 1993.

E-mail: dossantosrobinson@gmail.com

Recebido em: Setembro/2010

Aprovado em: Dezembro/2010 